\title{
Risk factors for glucose intolerance in active acromegaly
}

\section{E. Kreze- Kreze \\ -Spirova ${ }^{1}$ and M. Mikulecky²}

\author{
${ }^{1}$ Institute of Endocrinology, Lubochna, Slovak Republic \\ ${ }^{2}$ Institute of Preventive and Clinical Medicine, Bratislava, \\ Slovak Republic
}

\section{Correspondence}

\section{A. Kreze}

Institute of Endocrinology

SK-03491 Lubochna

Slovak Republic

Fax: + 42-1-848-912-73

E-mail: mikuleky@upkm.sk

Received June 12, 2001

Accepted August 27, 2001

\section{Abstract}

In the present retrospective study we determined the frequency of glucose intolerance in active untreated acromegaly, and searched for risk factors possibly supporting the emergence of the diabetic condition. Among 43 patients, 8 (19\%; 95\% CI: 8-33\%) had diabetes mellitus and $2(5 \% ; 1-16 \%)$ impaired glucose tolerance. No impaired fasting glycemia was demonstrable. The frequency of diabetes was on average 4.5 times higher than in the general Slovak population. Ten factors suspected to support progression to glucose intolerance were studied by comparing the frequency of glucose intolerance between patients with present and absent risk factors. A family history of diabetes and arterial hypertension proved to have a significant promoting effect $(\mathrm{P}<0.05$, chi-square test). A significant association with female gender was demonstrated only after pooling our data with literature data. Concomitant prolactin hypersecretion had a nonsignificant promoting effect. In conclusion, the association of active untreated acromegaly with each of the three categories of glucose intolerance (including impaired fasting glycemia, not yet studied in this connection) was defined as a confidence interval, thus permitting a sound comparison with the findings of future studies. Besides a family history of diabetes, female gender and arterial hypertension were defined as additional, not yet described risk factors.

\section{Key words} - Acromegaly

- Diabetes mellitus

- Impaired glucose tolerance

- Impaired fasting glycemia

- Risk factors

- Inferential statistics

\section{Introduction}

Acromegaly, a clinical syndrome caused by autonomous hypersecretion of growth hormone, is frequently associated with glucose intolerance. While the occurrence of diabetes mellitus has been repeatedly evaluated in patients with acromegaly, with estimates of 19 to $56 \%$ (1-6), that of the intermediate form of disturbed glucose metabolism, referred to as impaired glucose tolerance, was analyzed, to the best of our knowledge, only in two recent studies $(6,7)$. No evaluation of impaired fasting glycemia - a new category of the intermediate disorder of glucose metabolism $(8,9)$ - in acromegaly has been performed thus far.

A well-known major cause of glucose intolerance in acromegaly is insulin resistance (10-12) induced by growth hormone and its mediator, insulin-like growth factor type 1. Other risk factors (e.g., a long duration of active acromegaly and older patient age) may promote the development of glu- 
cose intolerance. Nevertheless, relevant clinical studies are scarce $(2,6)$.

Therefore, the aim of the present study was to assess the frequency of all three categories of diabetic disease (i.e., diabetes mellitus, impaired glucose tolerance, impaired fasting glycemia) in Slovak patients with acromegaly, and to extend the few existing scrutinies of possible risk factors for glucose intolerance in acromegaly.

\section{Patients and Methods}

The records of 43 patients with active untreated acromegaly (10 males and 33 females aged 20-71 years, on average 45.7 years), diagnosed during the years 1990-99 at the Institute of Endocrinology (Lubochna, Slovak Republic) were reviewed. Typical signs of acromegaly were present in all 43 patients. The diagnostic investigation at the Institute of Endocrinology was performed over a period of 1-15 years, on average 5.8 years since the onset of the signs of acromegaly. The diagnosis of active acromegaly was based on sustained elevation of serum growth hormone levels that were not suppressible below $4 \mathrm{mU} / \mathrm{l}$ in the $75 \mathrm{~g}$ oral glucose tolerance test. This test was not performed in patients with a history of diagnosed diabetes mellitus. The diagnosis of active acromegaly was then based on integrated serum growth hormone values (mean of five measurements during $24 \mathrm{~h}$ ) above $10 \mathrm{mU} / \mathrm{l}$. The morning level of serum prolactin was routinely determined in every patient.

Plasma glucose concentrations were determined by the glucose oxidase method (Beckman Glucoanalyser, Beckman Instruments, Fullerton, CA, USA). The results were retrospectively reviewed according to the diagnostic criteria of the American Diabetes Association (8). In patients with a history of already diagnosed diabetes mellitus, the daily glucose levels (morning fasting plasma glucose plus 3 to 7 additional glycemia readings) were measured several times during the patients' stay at the Institute of Endocrinology. Repeated morning fasting plasma glucoses values $\geq 7.0 \mathrm{mmol} / \mathrm{l}$ confirmed the diagnosis of known diabetes mellitus. In all other patients, the $75 \mathrm{~g}$ oral glucose tolerance test was routinely performed. The diagnostic criterion for diabetes mellitus was a 2 -h plasma glucose value $\geq 11.1 \mathrm{mmol} / \mathrm{l}$. A 2 -h plasma glucose value $\geq 7.8 \mathrm{mmol} / \mathrm{l}$ but $<11.1 \mathrm{mmol} / \mathrm{l}$ indicated impaired glucose tolerance, and fasting plasma glucose $\geq 6.1$ but $<7.0 \mathrm{mmol} / 1$ indicated impaired fasting glycemia.

Serum growth hormone levels were measured by immunoradiometric assay $(\mathrm{GH}$ IRMA kit, Immunotech, a Beckman Coulter Company, Marseille, France). The sensitivity of the assay was $0.10 \mathrm{mU} / \mathrm{l}$ and the intraand interassay coefficients of variation were 1.5 and $14.03 \%$, respectively. Serum prolactin levels were estimated by immunoradiometric assay (IRMA-mat Prolactin kit, BykSangtec Company, Dietzenbach, Germany). The sensitivity of the assay was $<10 \mathrm{mU} / \mathrm{l}$ and the intra- and interassay coefficients of variation were 8.3 and $10.6 \%$, respectively.

As to the pituitary tumor staging, computed tomographic scan or magnetic resonance imaging revealed intrasellar pituitary microadenomas (diameter $<10 \mathrm{~mm}$ ) in 11 patients, intrasellar macroadenomas in 10 , expansive macroadenomas in 15 , and invasive macroadenomas in 7.

The variables studied possibly promoting glucose intolerance were as follows: patient gender (females versus males), patient age at the time of diagnostic investigation ( $\geq 40$ years versus $<40$ years), duration of acromegaly at this time ( $\geq 6$ years versus $<6$ years), a family history of diabetes (positive versus negative), obesity (body mass index $\geq 30 \mathrm{~kg} / \mathrm{m}^{2}$ versus $<30 \mathrm{~kg} / \mathrm{m}^{2}$ ), arterial hypertension ( $\geq 140 / 90 \mathrm{mmHg}$ versus absent), hirsutism in female patients ( $\geq 8$ points according to Ferriman and Galwey's estimate (13) versus absent), integrated serum growth hormone value $(\geq 50 \mathrm{mU} / \mathrm{l}$ versus $<50 \mathrm{mU} / \mathrm{l})$, 
hyperprolactinemia (prolactin level $\geq 400$ $\mathrm{mU} / \mathrm{l}$ versus $<400 \mathrm{mU} / \mathrm{l}$ ), and pituitary macroadenoma (adenoma diameter $\geq 10 \mathrm{~mm}$ versus $<10 \mathrm{~mm}$ ).

All proportions, e.g., those of subjects with glucose intolerance in relation to the total group, were expressed as point estimates of percentage with the $95 \%$ confidence intervals (95\% CI) based on binomial distribution (14).

In the search for factors playing a role in the manifestation of glucose intolerance, the data were always divided according to the presence or absence of each variable into two groups, e.g., female versus male subjects. In either group, the percentage of subjects with glucose intolerance and its $95 \% \mathrm{CI}$ were calculated. The difference in percentage between groups was evaluated by the chi-square test.

\section{Results}

Glucose intolerance was present in 10 subjects, i.e., in $23 \%$ (95\% CI: $12-39 \%$ ) of the total of 43 acromegalics. Eight (19\%; 95\% CI: 8-33\%) of them had diabetes mellitus, confirmed by our glycemia measurements. Diabetes mellitus manifested at the onset of acromegaly in 2 subjects and developed after its onset in 6 . Of these 8 diabetics, 4 were treated with insulin, 2 were on oral hypoglycemic agents and 2 on diet alone. Two cases (5\%; 95\% CI: $1-16 \%)$ of impaired glucose tolerance were revealed de novo. Impaired fasting glycemia was not detected.

Table 1 lists the outcome of the study of the influence of ten factors putatively promoting the development of glucose intolerance.

\section{Discussion}

This is the first study of all three categories of glucose intolerance in acromegaly, i.e., of diabetes mellitus, impaired glucose tolerance and impaired fasting glycemia. It is also the first study of this kind performed in Slovakia. The frequency of diabetes mellitus (19\%) found in patients with active untreated acromegaly was on average 4.5 times higher than the prevalence of diabetes mellitus reported to be $4.18 \%$ (95\% CI: 4.16$4.19 \%$ ) by the Institute of Health Information and Statistics of the Slovak Republic (15) for the whole population of Slovakia (5,387,650 inhabitants).

The $19 \%$ frequency of diabetes, and particularly its confidence interval (8-33\%) compare well with the $19 \%$ frequency of diabetes mellitus reported for the sample of acromegalics in the United Kingdom by

Table 1. Association of ten factors with glucose intolerance (GI\%) in 43 acromegalics.

\begin{tabular}{|c|c|c|c|c|c|c|c|}
\hline \multirow[t]{2}{*}{ Factor } & \multicolumn{3}{|c|}{ Factor present } & \multicolumn{3}{|c|}{ Factor absent } & \multirow{2}{*}{$\begin{array}{l}\text { Chi-square for } \\
\text { difference }\end{array}$} \\
\hline & $\mathrm{N}$ & $\mathrm{GI} \%$ & $95 \% \mathrm{Cl}$ & $\mathrm{N}$ & $\mathrm{GI} \%$ & $95 \% \mathrm{Cl}$ & \\
\hline Female gender & 33 & 27 & (13-46) & 10 & 10 & $(0-45)$ & 1.5918 \\
\hline Age ( $>40$ years) & 28 & 29 & (13-49) & 15 & 13 & $(2-40)$ & 1.4127 \\
\hline Duration ( $>6$ years) & 17 & 35 & $(14-62)$ & 26 & 15 & $(4-35)$ & 2.2336 \\
\hline Family history of diabetes & 13 & 46 & (19-75) & 30 & 13 & $(4-31)$ & $5.0504 *$ \\
\hline Obesity & 17 & 35 & $(14-62)$ & 26 & 15 & $(4-35)$ & 2.2336 \\
\hline Hypertension & 13 & 46 & $(19-75)$ & 30 & 13 & $(4-31)$ & $5.0504 *$ \\
\hline Female hirsutism & 6 & 50 & $(12-88)$ & 27 & 22 & $(9-42)$ & 1.7032 \\
\hline Growth hormone (>50 mU/l) & 12 & 42 & $(15-72)$ & 31 & 16 & $(5-34)$ & 2.8782 \\
\hline Hyperprolactinemia & 15 & 33 & $(12-62)$ & 28 & 18 & $(6-37)$ & 1.2545 \\
\hline Pituitary macroadenoma & 32 & 22 & $(9-40)$ & 11 & 27 & $(6-61)$ & 0.1290 \\
\hline
\end{tabular}

$\mathrm{N}=$ sample size; $95 \% \mathrm{Cl}=95 \%$ confidence interval.

$* \mathrm{P}<0.05$ compared to acromegalics with absent factor (chi-square test).

Table 2. Association of the factor female gender with glucose intolerance before and after recalculation by summing the data from two sources.

\begin{tabular}{|c|c|c|c|c|c|c|c|}
\hline \multirow[t]{2}{*}{ Source } & \multicolumn{3}{|c|}{ Factor present } & \multicolumn{3}{|c|}{ Factor absent } & \multirow{2}{*}{$\begin{array}{c}\text { Chi-square for } \\
\text { difference }\end{array}$} \\
\hline & $\mathrm{N}$ & $\mathrm{GI} \%$ & $95 \% \mathrm{Cl}$ & $\mathrm{N}$ & $\mathrm{GI} \%$ & $95 \% \mathrm{Cl}$ & \\
\hline Present paper & 33 & 27 & $(13-46)$ & 10 & 10 & $(0-45)$ & 1.5918 \\
\hline Nabarro (2) & 123 & 23 & $(16-31)$ & 133 & 15 & $(9-22)$ & 2.5127 \\
\hline $\begin{array}{l}\text { Present paper }+ \text { Nabarro }(2) \\
\text { (pooled) }\end{array}$ & 156 & 24 & $(17-31)$ & 143 & 15 & $(9-22)$ & 3.9736* \\
\hline
\end{tabular}

$\mathrm{N}=$ sample size; $\mathrm{Gl}=$ glucose intolerance; $95 \% \mathrm{Cl}=95 \%$ confidence interval. $* \mathrm{P}<0.05$ compared to male acromegalics (chi-square test). 
Nabarro (2), with the $20 \%$ frequency found among acromegalics of Maryland (USA) by Emmer et al. (1), with the $24 \%$ frequency found in Italian acromegalics by Arosio et al. (3), and with the $32 \%$ frequency ascertained among German patients by Biering et al. (6). On the other hand, the frequency rates of diabetes mellitus were well above our upper confidence limit in acromegalic patients of Indian origin and in patients from Hong Kong (56 and $50 \%$, respectively $(4,5))$. The differences in the size of patient samples and in ethnicity may have contributed to these discrepant findings.

The category of impaired glucose tolerance, an intermediate form of disturbed glucose metabolism, was assessed in only two studies on acromegaly. In both of them the frequency rates were above our upper $95 \%$ confidence limit (16\%), being $31 \%$ in German acromegalics (6) and $46 \%$ in Japanese acromegalics (7). The second, recently recognized $(8,9)$ intermediate form of glucose intolerance, named impaired fasting glycemia, was not detected in the present study. Since the presence of this category of glucose intolerance in acromegaly has not been assessed by other investigators, a comparison could not be made. In general population studies, impaired fasting glycemia has been found less frequently than impaired glucose tolerance (16-18). Our negative outcome in acromegaly is therefore not a surprise.

As to the risk factors promoting the development of glucose intolerance in acromegaly, Nabarro (2) claimed a significant tendency towards the occurrence of symptomatic diabetes in the presence of higher levels of growth hormone, older age and longer duration of acromegaly. Biering et al.
(6) found a predisposing influence for older age only. Analysis of our sample shows similar but statistically nonsignificant associations. The significant results obtained in the present study indicate that glucose intolerance in acromegaly develops in association with a family history of diabetes and with the presence of arterial hypertension. The predisposing influence of family history of diabetes on diabetes mellitus development in acromegaly is suggested by some textbooks (19-21), although this statement was not corroborated by quantitative data. The association with arterial hypertension has not been described previously. We have no explanation for such an association. The expected connection between hyperprolactinemia and glucose intolerance appeared to be nonsignificant while the connection with pituitary macroadenoma was completely absent. A positive association between glucose intolerance and female gender, found to be nonsignificant by ourselves and Nabarro (2), reached a significant level after the samples reported in the two studies were pooled (Table 2).

In conclusion, the association of active untreated acromegaly with each of the three categories of glucose intolerance (including impaired fasting glycemia, not yet studied in this connection) was defined as confidence interval, thus permitting sound comparison with future studies. Female gender and arterial hypertension were identified as newly recognized risk factors. Other reasonable associations found to be nonsignificant in the present study, possibly because of the small sample size, might become significant after pooling the samples, as shown for female gender. 


\section{References}

1. Emmer M, Gorden P \& Roth J (1997). Diabetes in association with other endocrine disorders. Medical Clinics of North America, 55: 1057-1063.

2. Nabarro J DN (1987). Acromegaly. Clinical Endocrinology, 26: 481-512.

3. Arosio M, Macchelli S, Rossi CM, Casati C, Biella O \& Faglia G (1995). Effects of treatment with octreotid in acromegalic patients - a multicenter Italian study. European J ournal of Endocrinology, 133: 430-439.

4. Arya $K R$, Pathare $A V$, Chadda $M \&$ Menon PS (1997). Diabetes in acromegaly - a study of 34 cases. J oumal of the Indian Medical Association, 95: 546-547.

5. Ko GT, Yeung VT, Chow CC \& Cockram CS (1999). Clinical characteristics of acromegaly in Hong Kong. Endocrine Research, 25: 195-206.

6. Biering $\mathrm{H}$, Knappe $\mathrm{G}$, Gerl $\mathrm{H} \&$ Lochs $\mathrm{H}$ (2000). Prevalence of diabetes in acromegaly and Cushing's disease (in German). Acta Medica Austriaca, 27: 27-31.

7. Kasayama S, Otsuki M, Takagi M, Saito $H$, Sumitani S, Kouhara H, Koga M, Saitoh $Y$, Ohnishi T \& Arita A (2000). Impaired betacell function in the presence of reduced insulin sensitivity determines glucose tolerance status in acromegalic patients. Clinical Endocrinology, 52: 549-555.

8. American Diabetes Association (1997). Report of the Expert Committee on the Diagnosis and Classification of Diabetes Mellitus. Diabetes Care, 20: 549-555.
9. Alberti KGMM \& Zimmet PZ (1998). Definition, diagnosis and classification of diabetes mellitus and its complications. Part I. Diagnosis and classification of diabetes mellitus. Provisional report of a WHO consultation. Diabetic Medicine, 15: 539-553.

10. Foss MC, Saad MJA, Paccola GMGF, Paula FJ A, Piccinato CE \& Moreira AC (1991). Peripheral glucose metabolism in acromegaly. J ournal of Clinical Endocrinology and Metabolism, 72: 1048-1053.

11. Melmed S, Ho K, Klibanski A, Reichlin S \& Thorner M (1995). Recent advances in pathogenesis, diagnosis, and management of acromegaly. J oumal of Clinical Endocrinology and Metabolism, 80: 33953402.

12. Wasada $T$, Aoki $K$, Sato A, Katsumori $K$, Muto $\mathrm{K}$, Tomonaga O, Yokoyama $\mathrm{H}$, Iwasaki N, Babazono T, Takahashi C, Iwamoto Y, Omori Y \& Hizuka A (1997). Assessment of insulin resistance in acromegaly associated with diabetes mellitus before and after transphenoidal adenectomy. Endocrinologia J aponica, 44: 617-620.

13. Ferriman D \& Galwey J D (1961). Clinical assessment of body hair growth in women. J ournal of Clinical Endocrinology, 21: 1440-1447.

14. Diem K \& Seldrup J (1982). Geigy Scientific Tables. Vol. 2. Introduction to Statistics. Statistical Tables. Mathematical Formulae. Ciba-Geigy, Basel, 104-107.

15. Institute of Health Information and Statis- tics of the Slovak Republic (1999). Health status of population. In: Health Statistics Yearbook of the Slovak Republic 1997. Bratislava, 27-82.

16. Larsson H (1998). Comparison of ADA and WHO criteria for diagnosis of diabetes and glucose intolerance. Diabetologia, 41: 1124-1125.

17. DECODE - Study Group (1999). Is fasting glucose sufficient to define diabetes? Epidemiological data from 20 European studies. Diabetologia, 42: 647-654.

18. Gabir MM, Hanson RL, Dabelea D, Imperatore G, Roumain J , Bennet PH \& Knowler WC (2000). The 1997 American Diabetes Association and 1999 World Health Organization criteria for hyperglycaemia in the diagnosis and prediction of diabetes. Diabetes Care, 23: 1108-1112.

19. Ganda OP (1994). Secondary forms of diabetes. In: Kahn CR \& Weir GS (Editors), J oslin's Diabetes Mellitus. Lea and Febiger, Philadelphia, 300-316.

20. Watkins PJ , Drury PL \& Howell SL (1996). Diabetes and its Management. Blackwell Science, Oxford, 27.

21. Kahn SE, McCulloch DK \& Porte J r D (1997). Insulin secretion in the normal and diabetic human. In: Alberti KGMM, Zimmet P, DeFronzo RA \& Keen H (Editors), International Textbook of Diabetes Mellitus. 2nd edn. J. Wiley \& Sons, New York, 338-353. 